\title{
AN OVERVIEW OF EARTHQUAKE INSURANCE IN JAPAN
}

\author{
M. Matsushima
}

\author{
Presented at the conference on \\ INFORMATION NEEDS OF THE EARTHOUAKE INSURANCE INDUSTRY \\ held in Christchurch, November 1989
}

\section{EARTHQUAKE INSURANCE IN JAPAN}

(1) Japanese fire insurance has a distinctive characteristic which differs from that of Europe and the U.S. That is, in Japan fire damage caused by an earthquake is considered earthquake damage and is not covered by fire insurance. Therefore, to deal with this risk one must obtain earthquake insurance in the form of either an independent insurance policy or an extended coverage endorsement.

(2) Two kinds of earthquake insurance are now practiced in Japan. One is the earthquake insurance on dwelling risks, under the Law concerning Earthquake Insurance, and the other provides cover for industrial risks. Although both of them are handled by private insurance companies, the former, being legislatively inspired, is clearly intended to contribute to the welfare of the public by providing coverage for buildings for residential use, exclusively or partially, and for chattels for household use.

Because of this contribution to the public welfare, the Government provides support by means of special reinsurance cover. Industrial risks are exclusively covered by private insurance companies in the form of an extended coverage endorsement to the ordinary fire policy.

In addition to the above mentioned earthquake insurance, extra expense coverage for dwelling houses is automatically included in the major fire insurance policies such as Dwelling House Fire Insurance, Householders' Comprehensive Insurance and Storekeepers' Comprehensive Insurance. General conditions of these fire insurance policies provide that in the event of damage caused by an earthquake related fire, consolation equal to $3 \%$ of the amount insured but not exceeding one million yen shall be paid.

* Director and General Manager, Fire and Casualty Insurance Department, Yasuda Fire and Marine Insurance Co. Ltd, Tokyo, Japan

\section{EARTHQUAKE INSURANCE ON DWELLING RISKS}

(1) Circumstances leading to the birth of

The Niigata Earthquake in 1964, which took place in the northwestern part of Japan, aroused public concern about the necessity of having some form of insurance scheme against earthquakes and gave impetus to the intensive study of that necessity. Thus, the Law concerning Earthquake Insurance was enacted on 1 June 1966.

Flanked by the Pan-Pacific earthquake zone, Japan has experienced a series of earthquake shocks with varying degrees of socio-economic effects. From its early days the Japanese insurance industry, acutely aware of the public demand for protection from disasters, had tried many times without success to thrash out a programme. Many reasons could be cited for the failure, but the main technical barriers are summarised in the following three points :

(a) Statistical frequency of earthquakes and probable measure of damage could not be ascertained, and also the so-called law of large numbers could not work efficiently.

(b) Extent of damage might sometimes be exorbitantly large defying human estimation, and in all probability the financial strength of the private insurance industry would not be sufficient to cope with the resultant claims.

(c) From past records, the shock-prone areas are easily discernible from the less prone ones, and this fact indicates the likely adverse selection for insurance.

Surmounting these hurdles, but by no means all, through assiduous technical studies, the earthquake insurance scheme came into being through special legislation. The insurance programme has since undergone revisions five times in order best to serve the objectives of providing insurance coverage to the public against catastrophe. 
(2) Outline of the programme.

Traditionally, under standard fire policies, not only shock damage but also damage caused by consequent fire is excluded in coverage, since homes of wooden construction, the most prevalent form of house building in Japan, are obviously very susceptible to fire resulting from earthquake. The earthquake insurance scheme fills this deficiency.

\section{(a) Subject-matter of insurance}

Subject-matter of insurance is confined to residential houses and/or household goods.

\section{(b) Method of acceptance}

Earthquake risks are underwritten by means of endorsements to ordinary fire policies or many types of fire comprehensive policies. This insurance is not compulsory; whether to effect insurance or not is entirely left to the discretion of individual assureds. The risks are always written in conjunction with fire risks and in no case are the risks per se accepted independently. (c) Amount insured

The amount of earthquake insurance is limited to somewhere between $30 \%$ and $50 \%$ of the sum insured in the main contract, either ordinary fire or comprehensive, but not exceeding $¥ 10,000,000$ on buildings and $¥ 5,000,000$ on contents respectively.

(d) Scope of coverage

This insurance covers loss or damage caused by fire, destruction, burying or washingaway following earthquake, volcanic erruption or tsunami. Unlike the earthquake cover on industrial risks, earthquake insurance on dwelling risks does not cover loss or damage less than $50 \%$ of the sum insured of the building (see Table 1).

(e) Tariff rates

The tariff rates were compiled based on the analysis of those earthquakes that were recorded during 485 years from 1494 to 1978 (see Table 2).

TABLE 1: SCOPE OF COVERAGE

\begin{tabular}{|c|c|c|}
\hline $\begin{array}{l}\text { Subject-matter } \\
\text { of insurance }\end{array}$ & Extent of damage & Indemnity \\
\hline \multirow[t]{2}{*}{ Building } & Total loss & $\begin{array}{l}\text { Total sum insured in the } \\
\text { earthquake insurance } \\
\text { (but not exceeding the } \\
\text { current value) }\end{array}$ \\
\hline & "Half loss" & $\begin{array}{l}50 \% \text { of the sum insured in } \\
\text { the earthquake insurance } \\
\text { (but not exceeding } 50 \% \text { of } \\
\text { the current value) }\end{array}$ \\
\hline \multirow[t]{2}{*}{ Contents } & Total loss & $\begin{array}{l}\text { Total sum insured in the } \\
\text { earthquake insurance } \\
\text { (but not exceeding the } \\
\text { current value) }\end{array}$ \\
\hline & $\begin{array}{l}\text { In case the damage } \\
\text { to the contents is } \\
\text { less than total } \\
\text { and the building } \\
\text { which held the said } \\
\text { contents sustained } \\
\text { total or "half loss" }\end{array}$ & $\begin{array}{l}10 \% \text { of the sum insured in } \\
\text { the earthquake insurance }\end{array}$ \\
\hline
\end{tabular}


TABLE 2: EARTHQUAKE INSURANCE PREMIUM RATE

\begin{tabular}{|c|c|c|c|c|}
\hline \multirow{2}{*}{ Structure } & \multicolumn{2}{|c|}{ Non-Wooden Structure } & \multicolumn{2}{|c|}{ Wooden Structure } \\
\cline { 2 - 5 } Location & building & contents & building & contents \\
\hline 1st class & $0.70\left(\boldsymbol{x}_{)}\right)$ & $0.50(\boldsymbol{x})$ & $2.30(\boldsymbol{x})$ & $1.70(\boldsymbol{x})$ \\
\hline 2nd class & 0.80 & 0.60 & 2.90 & 2.00 \\
\hline 3rd class & 1.40 & 1.00 & 3.70 & 2.60 \\
\hline 4th class & 1.60 & 1.10 & 4.20 & 3.00 \\
\hline 5th class & 1.80 & 1.30 & 4.80 & 3.40 \\
\hline
\end{tabular}

(e.g.) 5th class Region: Tokyo, Kanagawa and Shizuoka Prefectures.

Unit : Per thousand yen of the sum insured.

\section{(f) Aggregate limit of indemnity}

Considering a catastrophe case beyond all imagination an aggregate limit of indemnity payable by all insurers to all the claimants in respect of any one earthquake is decided upon every year by the Diet. Now it stands at $¥ 1,500$ billion.

(g) Reinsurance schemẹ

Simultaneously with the enactment of the Law concerning Earthquake Insurance in May 1966, the Japan Earthquake Reinsurance Co., Ltd. (hereinafter referred to as the JER) was established by all Japanese non-life insurance companies, and all the earthquake risks written by domestic and foreign direct insurers have been wholly reinsured with the JER. The JER's portfolio has in turn been protected by two excess of loss covers, one arranged with the direct insurers and the Toa Fire \& Marine Reinsurance $C o$. and the other arranged with the Government under the above Law.

For the year 1989 any earthquake loss was to be covered by (1) the JER, (2) direct insurers and the Toa Re. and (3) the Government respectively as follows :

(a) The JER was to bear first loss up to $¥ 40$ billion throughout the year.

(b) The direct insurers and the Toa Re. were to bear loss up to 15 billion in excess of $\$ 0$ billion throughout the year.

(c) Out of 225 billion in excess of $¥ 55$ billion, $50 \%$ or $¥ 112.5$ billion was to be borne by the Government for any one event, and out of the remaining $50 \%$ or $¥ 112.5$ billion was to be borne by the direct insurers and the Toa Re. throughout the year for any one event.

(d) Out of 1,220 billion in excess of $¥ 280$ billion, $95 \%$ or $¥ 1,159$ billion was to be borne by the Government, and out of the remaining $5 \%$ or 81 billion, $¥ 12.5$ billion was to be borne by the direct insurers and the Toa Re. throughout the year and $¥ 48.5$ billion in excess of $¥ 12.5$ billion was to be borne by the JER for any one event.

As the positions of the above three parties after any of the limits throughout the year as stated in (a) to (c) above is exhausted by one or more earthquake in the year are very much complicated, the explanation thereof is omitted here, but in any case the total amount to be borne by the direct insurers and the Toa Re. throughout the year should not exceed $¥ 140$ billion.

\section{Example 1}

If only one earthquake occurs in the year with total claims of 120 billion, the final liability of each party shall be as follows (figures in billion yen).

(i) Government: $(120-55) \times 50 \%$

(ii) JER

$=32.5$

(iii) Direct insurers and Toa Re. $15+(120-55) \times 50 \%$

$=40.0$

Total $\quad=\frac{47.5}{120.0}$

Example 2

If two earthquakes $A$ and $B$ occur in the year with total claims of $¥ 20$ billion and $¥ 300$ billion respectively, the final liability of each party shall be as follows (figures in billion yen):

(i) Government:

For A:

Nil

$(280-55) \times 50 \%+(300-280) \times 95 \%=131.5$ Total $-\frac{131.5}{131.5}$

(ii) JER:

For A: $\quad=20.0$

For B: $\quad$ Total $=\frac{40.0}{60.0}$

(iii) Direct Insurers and Toa Re: For A:

For B:

$\mathrm{Nil}$

$15+(280-55) \times 50 \%+(300-280) \times 5 \%=128.5$ Total $\frac{128.5}{128.5}$

Grand Total 320.0 


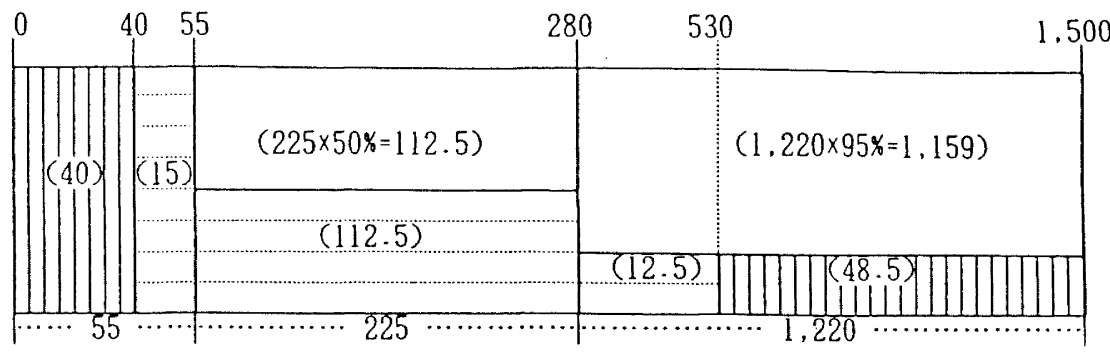

ПIII Borne by JER (Total $¥ 88.5$ billion)

…:. Borne by the direct insurers and Toa Re. (Total $¥ 140$ billion)

Borne by Government (Total $¥ 1.271 .5$ billion)

FIGURE 1: SUMMARY OF INSURANCE SCHEME (in billion yen)

Under the above scheme, the distribution of earthquake premiums among the above three parties is calculated every month by the JER according to the district and proportions of classified building structures. Fundamental data for the above calculation depend upon the study of 349 destructive earthquakes that happened in Japan over a period of 485 years from 1494 to 1978 .

Roughly speaking the earthquake premiums in March of 1989 were distributed in the following shares:

$\begin{array}{lcc}\text { Direct insurers and Toa Re } & 26 \% \\ \text { JER } & & 33 \% \\ \text { Government } & \ddots & 41 \%\end{array}$

(h) Deposit with the JER

The direct insurers and the Toa Re. have to deposit the whole amount of retrocession premiums with the JER, who in turn invests the fund on their behalf. Retrocession premiums by the JER are, therefore, ceded only as book entries and no actual settlement is made. Income accruing from such investment is also reserved by the JER on their behalf.

(i) Premium Reserve

Insurers are required to reserve, cumulatively from year to year, the whole amount of the pure premium income less net expenses as premium reserve. Actually, however, the assets corresponding to this premium reserve are all deposited with JER as mentioned above. Income accruing from the investment of the deposit fund should also be transferred. into this premium reserve. Withdrawal from this reserve fund is not allowed except for payment of earthquake claims.

\section{CALCULATION OF PREMIUM RATES FOR EARTHQUAKE INSURANCE}

Premium rates for insurance comprise two elements: the pure premium rate and the loading rate. The former covers the amount of claim payable when structures and household goods are damaged by earthquake. The latter covers the expense of operating the insurance business (including commissions for agents who solicit insurance policies).

The two portions are to be substantiated based on the principle that income should be commensurate with outgo. In fact, the Law concerning Earthquake Insurance (Law No.73, 1966) provides in Article 5 that the premium rate shall be as low as possible provided that income covers outgo. Although private insurance companies usually take into account an appropriate rate of profit in the rate-making, this profit element should not be counted in the premium rate for earthquake insurance.

\section{(1) Calculation of Pure Premium Rate}

In order to calculate the pure premium rate for earthquake insurance, it is first necessary to collect data on earthquakes as far back as records exist. Some years may pass without earthquakes that cause any serious loss or damage, while in other years large-scale earthquakes may occur one after another. Unlike fire damage, which takes place at a regular frequency, we can hardly estimate the frequency of earthquakes and the amount of damage that will result.

Thus, a record of the earthquakes that have occurred over hundreds of years is needed just to ascertain the average annual frequency of earthquakes.

Note: One of the basic principles underlying the non-life insurance system is the "Law of Large Numbers". According to this law, we can determine the regularity or probability of an occurrence from a large number of incidents which seem to occur at random. This law is also applicable to the calculation of the pure premium rate for earthquake insurance.

The recent progress of seismology has made it possible to analyse the earthquakes 
which have occurred since long ago. The procedure for calculating the pure premium rate based on these studies is as follows :

(1) The Annals of Science (52nd volume) compiled by the Tokyo Astronomical observatory show that 347 earthquakes causing loss or damage in Japan or its neighbouring regions were recorded from 1494 through 1976. Two earthquakes occurred in 1977 and 1978. In sum, 349 earthquakes occurring during the 485 years between 1494 and 1978 from the basic data for calculating the pure premium rate.

(2) Suppose that earthquakes of the same magnitude (Note 1) and with the same hypocenter (Note 2) as the aforementioned 349 earthquakes were to occur again in today's Japan. Recent seismology and earthquake engineering methods have made it possible to estimate the probable amount of loss or damage that would have been caused by each one of these earthquakes. Needless to say, this calculation varies according to the areas concerned, the type of building structure involved and the applicable standards for payment (total loss or half loss).

(3) If we take the sum of the probable amount of damage that would have been caused by each earthquake, the total amount of damage caused over 485 years is obtained. Thus, 1/485th of this sum would be the average amount of loss per year. Dividing this average amount by the amount insured, we can obtain the pure premium rate for earthquake insurance.

Note 1: Magnitude is the measurements of the force of an earthquake.

Note 2: Earthquakes are caused by the movement of masses of rock far beneath the earth's surface. The hypocenter of an earthquake is the area where the earthquake's destruction is initiated.

(2) Calculation of Loading Rate

The loading rate is composed of the elements shown in Figure 2 .

\section{(ii) Commission rate for insurance agents}

The commission rate for insurance agents compensates agents engaged in handling insurance contracts with applicants. This rate is lower than that for other ordinary non-life insurance contracts.

The basic materials used for calculating (i) and (ii) are the performance records upon which the financial statements of insurance companies are based.

4. Other Issues Concerning Earthquake

Insurance on Dwelling Risks

(1) Since earthquake insurance on dwelling risks is supported by the government reinsurance scheme in order to protect the public welfare, it should be used by as many people as possible. However, adverse selection easily occurs depending on the location of risks, and to confess, at present the ownership of this insurance is not sufficient; the ownership rate (household basis) as of March 1989 , is $8.2 \%$ only.

It is necessary for us to both reform the contents of the insurance and, in order to cooperate with the government policy of protecting the public welfare, to strive to raise the insurance ownership rate.

Issues from the standpoint administration include the following:

(a) Reinsurance

There is a support mechanism of government reinsurance, but the present scheme is not sufficient to deal with several giantic earthquakes and therefore calls for further consideration.

\section{(b) Cash Flow}

It is necessary to consider how to prepare for the colossal capital requirements that will ensue from the occurrence of a gigantic earthquake and also for the emergency for financial arrangement for such eventuality.

\begin{tabular}{|c|c|c|}
\hline Loading rate & Company expenses rate & Operating expenses \\
\hline & & $\begin{array}{l}\text { Expenses for claim } \\
\text { adjustment }\end{array}$ \\
\hline & $\begin{array}{l}\text { Commission rate } \\
\text { for insurance agents }\end{array}$ & \\
\hline
\end{tabular}

FIGURE

(c) Claim Adjustment

\section{(i) Company Expenses}

Company expenses include operating expenses and outlays for claim adjustment. The former covers the cost of handling insurance contracts (the cost of issuing insurance policies and computer processing), while the latter relates to the payment of claims and the cost of claim adjustment.
Present arrangements for large earthquake damage above a certain level are that emergency headquarters will be set up at the Marine and Fire Insurance Association of Japan with necessary personnel supplied by individual insurers, and a "joint settlement system" will be set up in order to make prompt payments based on industrywide uniform standards. However, it is not known where, when or what extent an earthquake will occur, so although the 
industry is making all preparations it ought to, there are aspects that can not be known until one actually occurs. Training before the disaster strikes is important. so the insurance industry is holding training exercises every year. Also, the data of earthquake insurance policies are stored in duplicate in both Tokyo and Osaka in order to ensure a prompt and smooth response by the data processing system in the event of a large earthquake.

\section{EARTHQUAKE INSURANCE ON INDUSTRIAL RISKS}

Unlike the earthquake insurance on dwellings this insurance is written by the private insurance industry for its own account without reinsurance support from the Government.

(1) Form of policy-Special Earthquake Coverage Endorsement

While recognising the technical difficulties in insuring earthquake risks, the Japanese insurance industry could hardly resist the cries from industrial circles for the creation of some form of coverage for these risks along with the protection against flood and windstorm. After careful study the insurance industry decided to respond to the request by introducing the special earthquake coverage endorsement to fire policies, patterned after the American form of extended coverage endorsements but with the necessary modifications, and commenced writing the business in November, 1956. At present, this endorsement is being sold by all licensed insurance companies.

oil refineries are the main purchasers of this insurance. An accumulation of risks is witnessed along the Pacific coastline in such areas as Tokyo, Nagoya and Osaka. This poses a knotty problem for the insurance industry because that capacity has to be weighted against the availability of reinsurance from the domestic and overseas markets.

Thus, a zoning idea was introduced whereby the Japanese archipelago is divided into twelve zones on the basis of the assumption that an area with the radius of 50 kilometres is a unit of exposure.

Under this zone system, the actual indemnity for loss or damage caused by earthquake is limited in several zones, by means of a Reduced Percentage Indemnity clause in the endorsement, to a certain percentage of the insured amount of the fire policy. The purpose of this limitation is to overcome difficulties in reinsurance arrangements in the domestic and overseas markets.

The percentages of indemnity are given in Table 3 .

\section{(2) Scope of coverage}

Earthquake risks must always be insured in conjunction with fire risks, and also, the subject matter of this insurance should be identical with that of the fire policy. This insurance covers the following types of damage :

(i) damage caused by or arising out of fire following earthquake.

(ii) destruction or burying caused by earthquake. (These risks can be excluded by Earthquake Shocks Exclusion special clause.)

This insurance also covers the following types of damage at an additional premium :

(iii) resultant bursting and explosion following earthquake as per Earthquake Bursting and Explosion Coverage Special clause attached to the policy.

(iv) tsunami, flood or other water damage following earthquake as per Earthquake Water Damage Coverage Special clause attached to the policy.

TABLE 3: LIMITING PERCENTAGES OF INDEMNITY

\begin{tabular}{|c|c|c|}
\hline Zone No. & $\begin{array}{l}\text { For existing risks (excluding any } \\
\text { increase in the insured amount) }\end{array}$ & $\begin{array}{c}\text { For increases in the insur } \\
\text { ed amount or for new risks }\end{array}$ \\
\hline $5 *$ & $\begin{array}{l}\text { Same percentage of indemnity as } \\
\text { applied under the former policy }\end{array}$ & $15 \%$ or less \\
\hline 6 & $\begin{array}{l}60 \% \text { or the percentage of indem- } \\
\text { nity applied under the former } \\
\text { policy, whichever is the less }\end{array}$ & $30 \%$ or less \\
\hline $1,4.8 .9$ & $\begin{array}{l}\text { Same percentage of indemnity as } \\
\text { and } 12\end{array}$ & $30 \%$ or less \\
\hline
\end{tabular}

(e.g.)*Zone No.5 $\cdots 3$ prefectures comprehending Tokyo, Yokohama 
(3) Deductible

From all the loss or damage caused by each occurrence (within 72 hours after the shock as is the case with the earthquake insurance on dwelling risks) an amount equivalent to $2 \%$ of the insurable value (but not exceeding $¥ 100,000$ ) should be deducted.

\section{(4) Rates}

Basic rate is to be fixed on the basis of the susceptibility to destruction which is classified by the building structures and by locations classified according to the degree of earthquake exposure.

By modifying the basic rate by the
following rates and discount, the
applicable rate is worked out : additional
premium rates for (1) susceptibility to own
fire, (2) susceptibility to resultant
destruction (3) susceptibility to fire
spread and (4) special movable properties.

\section{FUTURE ISSUES CONCERNING EARTHQUAKE}

INSURANCE ON INDUSTRIAL RISKS

Due to the difficulty of obtaining reinsurance for special earthquake coverage endorsement, and due to the "sudden colossal payment" nature of the damage from a large earthquake, only a limited form of earthquake insurance can be sold. Also the issues of how smoothly reinsurance recoveries from overseas reinsurers can be obtained and of the so-called "security problems" of the reinsurers should be further considered.

\section{SOME COMMENTS}

Japanese insurance companies at present underwrite earthquake insurance in the way I have just explained. However, as I have pointed out there still remains some problems to be resolved. We all understand that those problems inherent in earthquake insurance can not be bypassed by the Japanese non-1ife insurance industry. Therefore, we are going to tackle those problems continuously and in a positive manner, and $I$ would like to invite your advice and your assistance. 